\title{
Protective Effects of Modeled Superoxide Dismutase Coordination Compound (MSODa) Against Ischemia/Reperfusion Injury in Rat Skeletal Muscle
}

\author{
Xin-Tao Wang Ye Tian Wen-Xiao Xu Li-Huang Cui Shou-Yang Xiang \\ Song-Cen Lü
}

Department of Orthopedic Surgery, the $2^{\text {nd }}$-Affiliated Hospital of Harbin medical University, Harbin, China

\section{Key Words}

Superoxide dismutase $\cdot$ Free radicals $\cdot$ Adherent molecules $\bullet$ Ischemia/reperfusion $•$ Skeletal muscle

\begin{abstract}
Background/Aim: Ischemia/reperfusion (I/R) injury of skeletal muscles is common pathophysiology during surgeries and the superoxide dismutase (SOD) plays a critical role in this process. SOD-modeled coordination compound (MSODa) may simulate the protective effects as SOD. Methods: Therefore, this study was designed to explore the protective effects and underlying mechanism of MSODa on malondialdehyde (MDA) and integrin- $\beta 2$ (CD11b/ CD18) in plasma, myeloperoxidase (MPO) and intercellular cell adhesion molecule-1 (ICAM1 ) in tissue, and morphological changes before and after $I / R$ injury. The rat model of $I / R$ in hind limb was established and randomly divided into sham, ischemia, I/R, I/R-treated with saline, SOD, and MSODa, respectively. Results: These results showed that averaged values for MDA, MPO, CD11b/CD18, and ICAM-1 were significantly increased $(P<0.01$ vs ischemia alone) in a time-dependent fashion along with marked tissue remodeling, such as abnormal arrangement of muscular fibers, interstitial edema, vasodilation with no-reflow, inflammatory cells adherent and infiltration, structural changes in mitochondrial, and decrease in glycogens as well. However, all parameter changes induced by I/R injury were reversed, at least partially, by MSODa and SOD treatments and intriguingly, the beneficial/protective effects of MSODa was superior to SOD with an early onset. Conclusion: This novel finding demonstrates that MSODa improves I/R injury of skeletal muscles due at least partially to inhibition of adherent molecule expression and reduction of oxygen free radical formation during I/R pathophysiological processes and this protective action of MSODa was superior to SOD, highlighting the bright future for MSODa in clinical management of tissue I/R injury.




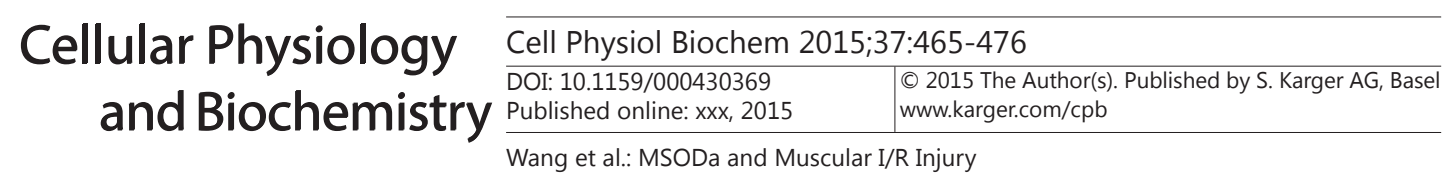

\section{Introduction}

The skeletal muscle ischemia-reperfusion (I/R) injury is a pathophysiological process during surgeries and post-surgical management in clinical practice, commonly seen in limb reattachment [1], limb vascular damage [2], osteofascial compartment syndrome [35], and free flap transplantation [6], which will directly affect the succeed of the operation especially in the division of orthopedics and the quality of life. It has well been accepted that skeletal muscle I/R injury is caused by free radicals produced from oxidative stress [7] and leukocytes play a key role in the pathogenesis of skeletal muscle I/R injury [8-11], which is preconditioned by the expression of adhesion molecular on leukocytes and endothelia [1214]. Large scale of evidences have also demonstrated that the superoxide dismutase (SOD) is an important to control reactive oxygen species during I/R injury $[15,16]$, but the relevance to human disease conditions mentioned above and the potential mechanism underlying I/R injury is not clarified. Moreover, looking for a therapeutic agent to replacement of SOD would be worthy of attempting due to the sources and cost for utilizing the SOD. Therefore, this study was designed to explore the protective effects of both SOD and modeled SOD coordination compound (MSODa) [17], an artificially synthesed compound $\mathrm{Cu}_{2}\left(\mathrm{C}_{3} \mathrm{~N}_{2} \mathrm{H}_{4}\right)_{6}\left(\mathrm{C}_{3} \mathrm{H}_{2} \mathrm{H}_{2}\right) \mathrm{Cl}_{3}$ based upon the natural $\mathrm{Cu}-\mathrm{Zn}$ (Cu-ZnSOD) showing similar property and the structure with molecular weight at only 708.5, and extracellular activity compared with natural SOD, on plasma MDA, tissue MPO, CD11b/CD18 positive neutrophils, and ICAM-1 positive vasculatures, and morphological changes before and after skeletal muscle I/R injury in rats. The current observation demonstrates that the protective effects of MSODa against I/R injury-induced by oxidative stress is superior to SOD.

\section{Materials and Methods}

\section{Experimental animals}

For duplicate I/R models of skeletal muscle of rats, adult male Wistar rats with body weight between 200-220 g were purchased from Experimental Animal Center of the $2^{\text {nd }}$ Affiliated Hospital of Harbin Medical University (Certification №: SCXK-20-120-002). All rats were maintained in the animal facility with 12 hour light cycle. Experimental protocols used in this experiment have been preapproved by the Institutional Animal Care and Use Committee of School of Medical Science, Harbin Medical University. All animal experiments were conducted by following the Principles of laboratory animal care (NIH publication no. 85-23, revised 1985; http://grants1.nih.gov/grants/olaw/references/phspol.htm), as well as specific national laws where applicable.

\section{Chemicals}

Monoclonal antibodies for ICAM-1 (MCA733), CD11b-RPE (MCA711PE), and CD18-FITC (MCA775F) were purchased from AbD Serote ${ }^{\circledR}$ Bio Comp (Oxford, UK). Biotin goat anti mouse IgG antibody, poly-D lysine, SABC kits, and DAB color rendering kits were ordered from Boster Bio (Wuhan, China). SOD (specific activity: 8000 units/mg), MSODa (MW: 708.5, molecular formula: $\mathrm{Cu}_{2}\left(\mathrm{C}_{3} \mathrm{~N}_{2} \mathrm{H}_{4}\right)_{6}\left(\mathrm{C}_{3} \mathrm{~N}_{2} \mathrm{H}_{3}-\mathrm{Cl}_{3}\right.$; sterile injection: $100 \mu \mathrm{g} / \mathrm{ml}$ ), MDA, and MPO kits were all purchased from the regular commercial sources.

\section{Equipments}

FACSort Cell Sorter Flow Cytometer (B.D., New Jersey, USA), emission electromicroscope (JEM-1220, Japanese Electronics Co., Lid., Kyoto, Japan), grating spectrophotometer (model 722, Analytical Instrument Comp., Shanghai, China), high speed centrifuge (model H-1600, Analytical Instruments, Comp., Shanghai, China), light microscope (Olympus, Tokyo, Japan), thermostatic waterbath (Medical equipments Comp., Beijing, China), and electrically heated drying oven (Hongda Medical Instruments Comp., Nantong, China) were used for designed measurements and tests.

Ischemia/reperfusion model

The skeletal muscle I/R model rats were prepared according to the procedures described in details previously [12]. Briefly, the rats were anesthetized by intraperitoneal 1\% pentobarbital sodium. After 


\section{Cellular Physiology Cell Physiol Biochem 2015;37:465-476 \begin{tabular}{ll|l} 
DOI: 10.1159/000430369 & $\begin{array}{l}\text { O 2015 The Author(s). Published by S. Karger AG, Basel } \\
\text { www.karger.com/cpb }\end{array}$ \\
and Biochemistry Published online: xxx, 2015 & Pang
\end{tabular} \\ Wang et al.: MSODa and Muscular I/R Injury}

completely relaxation, the skin on the left hind leg was sheared and sterilized with medical iodine and $70 \%$ alcohol, cut open along the knee, and blunts deserted subcutaneous tissue and muscles until completely expositing the joint. Following these procedures, both the sciatic and femoral nerves were cut, the pretibial and posttibial blood vessels were carefully separated toward proximal ends until the crotch of femoral artery and vein, and then the branches of femoral blood vessels were ligated and cut, the meanwhile, the periosteum on the distal femur was peeled with caution. At this point, the ischemia model was established by closing both femoral artery and vein together using proper size of non-invasive vascular clamp for $4 \mathrm{~h}$. Whereas, for the I/R injury model was established by reopen the clamp at 1, 2, 4, 8, and $12 \mathrm{~h}$ after ischemia. The sham operation was also performed upon the similar procedures without using vascular clamp. For the saline and test groups, $500 \mathrm{ml}$ saline, SOD (16000 unit $/ \mathrm{kg}$ ), or MSODa (400 $\mu \mathrm{g} / \mathrm{kg}$ ) were given intravenously at 5 min prior to the reperfusion, respectively.

\section{CD11b/CD18 expression neutrophils}

$10 \mu \mathrm{l} \mathrm{CD11b-RPE,} 10 \mu \mathrm{l} \mathrm{CD18-FITC,} \mathrm{and} \mu \mathrm{l} \mathrm{PBS}$ were added, respectively, into the test tubes containing $100 \mu \mathrm{l}$ heparinized whole blood to label monoclonal antibody MRC OX-42 and WT, well mixed with shaker in the darker room; and incubated at room temperature for $25 \mathrm{~min}$, and then adding red blood cell cracking liquid (10 times diluted) and standing for $10 \mathrm{~min}$ followed by centrifugation at $1500 / \mathrm{rpm}$ at room temperature for $5 \mathrm{~min}$. After removing the supernatant, the sample was washed with PBS twice and shaked well with additional $800 \mu \mathrm{l}$ PBS before the cytometry detection. By using Cellquest software, the rate of expression of CD11b/CD18 was analyzed (the percentage of CD11b/CD18 fluorescent positive neutrophils in total number of neutrophils in the tested sample).

\section{ICAM-1 expression in vasculature of skeletal muscle}

The tissue block was continuously sliced at $3 \mu \mathrm{M}$ and placed on the poly-D lysine coated coverslips, and then incubated at $37^{\circ} \mathrm{C}$ for before use; For dewaxing, the tissue slice was treated with xylene for 4 times with 10 min each, washed another 4 times with anhydrous alcohol to remove the xylene, and then washed once with $95 \%$ alcohol followed by $\mathrm{ddH}_{2} \mathrm{O}$; The tissue slice was merged into mixed solution of $0.3 \%$ methanol and hydrogen peroxide for $30 \mathrm{~min}$ and washed by PBS for 3 times with $5 \mathrm{~min}$ each; The slice was then place into the container with sodium citrate and heated up to $92^{\circ} \mathrm{C} \sim 98^{\circ} \mathrm{C}$ for $10 \sim 15 \mathrm{~min}$, after cooling at room temperature for $20 \mathrm{~min}$, the tissue slice was sealed using $5 \% \sim 10 \%$ goat serum at room temperature for $20 \mathrm{~min}$; After completely removing the goat serum, the slice was treated with $50 \mu \mathrm{l}$ PBS diluted primary antibody MCA-733 at $4^{\circ} \mathrm{C}$ overnight; following 3 times wash with PBS at 5 min each, biotinylated goat again mouse secondary antibody was added and incubated at room temperature for $30 \mathrm{~min}$; Following 3 times wash with PBS, the tissue slice was treated with DAB for appropriate time upon the observation under the light microscope, and stained with hematoxylin for the microscopy analysis. Continuous 20 with no overlapping field of visions was investigated ( $40 \mathbf{x}$ ) randomly and ICMA-1 positive vasculatures (\%) in total observed blood vessels were calculated.

\section{MDA determination}

$0.5 \mathrm{ml}$ whole blood was taken from femoral vein, heparinized and centrifuged at $3000 \mathrm{rpm}$ for 10 min to get the plasma. The amount of Methane Dicarboxylic Aldehyde (MDA) in plasma was determined by glucosinolates pentobarbital sodium and detail procedures of the measurements followed the instruction of the commercial kit using spectrophotometer and the OD value was directly read and presented as nmol/L.

\section{MPO measurement}

For this measurement, $5 \%$ tissue homogenate was prepared with the medium at the ratio of 9:1 and myeloperoxidase (MPO) in tissue was measured by reading the OD value at $460 \mathrm{~nm}$ using spectrophotometer and expressed as MPO unit/gram wet tissue.

\section{Microscopy}

The tissue was fixed with 10 15\% formaldehyde for $24 \mathrm{~h}$, and underwent with dehydration with gradient alcohol, transparent processing with xylene, embedded with paraffin and then the tissue block was sectioned to $4 \mu \mathrm{m}$ tissues slices, which was dewaxed and stained with hematoxylin, and then the slices were underwent transparent treatment, sealing for light microscope investigation. 


\section{Cellular Physiology Cell Physiol Biochem 2015;37:465-476

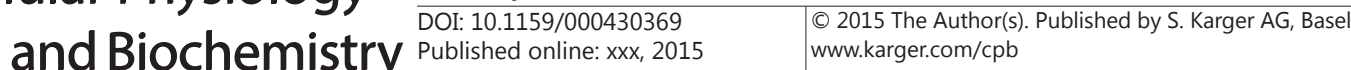 \\ Wang et al.: MSODa and Muscular I/R Injury}

\section{Electromicroscopy}

The tissue was cut into 1 cubic millimeter block, fixed with $2 \%$ glutaraldehyde for $1 \mathrm{~h}$, washed with $0.1 \%$ PBS buffer for 3 times; the above tissue block was fixed with $0.1 \%$ goose acid for $2 \mathrm{~h}$, and then dehydrated with gradient acetone, merged into epoxy resin over night; The fixed tissue block was sectioned into 50 100 nM slices and treated with 1\% venturi blue for electronic microscope observation.

\section{Statistical analysis}

Averaged data were presented as the mean \pm SD. The statistical analysis was performed with SAS software package and the student $t$-test, chi-square test, and ANOVA were applied where appreciate. The P values less than 0.05 were considered as the significant difference.

\section{Results}

Effects of MSODa on plasma MDA before and after ischemia/reperfusion injury of skeletal muscle

The MDA occurs naturally and is commonly used as a biomarker to measure the level of oxidative stress in an organism $[18,19]$, especially in I/R injury in both myocardial [20] and skeletal muscles [21]. In this regard, the MDA was tested and the results showed (Table 1) that, compared with sham, the amount of MDA was dramatically increased ( $4.94 \pm 0.53$ $\mathrm{nM}, P<0.01$ ) in the plasma of ischemic rats, which was further enhanced, at least double in amount, time-dependently following reperfusion in either I/R and saline-treated models and peaked at $8 \mathrm{~h}$ after I/R. Even though the increased values of MDA were also confirmed in SOD- and MSODa-treated groups, the values were significantly less than those seen in I/R

Table 1. Effects of SOD and SOD-modeled coordination compound (MSODa) on increased plasma malondialdehyde (MDA) and skeletal muscular myeloperoxidase (MPO) in each group before and after ischemia, ischemia/reperfusion (I/R) injury, and. Averaged data were expressed as mean $\pm \mathrm{SD}, n=6$ rats for each group. ${ }^{*} P<0.05$ and ${ }^{* *} P<0.01$ vs sham, ${ }^{\dagger} P<0.05$ and ${ }^{\dagger \dagger} P<0.01$ vs ischemia, ${ }^{\ddagger} P<0.05$ and ${ }^{* \ddagger} P<0.01$ vs I/R, ${ }^{\S} P<0.05$ and ${ }^{\S} P<0.01$ vs SOD. Note: Sham: sham operation group; I: ischemia group; I/R: ischemia/reperfusion group; Saline: I/R rats treated with normal saline group; SOD: I/R rats treated with SOD; MSODa: I/R rats treated with MSODa

\begin{tabular}{|c|c|c|c|c|c|}
\hline & & & MDA (nmol/L) after reperfusion & & \\
\hline Group & & $1 \mathrm{~h}$ & $2 \mathrm{~h}$ & $8 \mathrm{~h}$ & $12 \mathrm{~h}$ \\
\hline Sham & $2.42 \pm 0.19$ & & & & \\
\hline I & $4.94 \pm 0.53^{* *}$ & & & & \\
\hline $\mathrm{I} / \mathrm{R}$ & & $8.31 \pm 1.46^{* *+\dagger}$ & $9.43 \pm 0.75^{* *+\dagger} \quad 10.2 \pm 1.04^{* *+\dagger}$ & $12.6 \pm 0.71^{* *+\dagger}$ & $11.3 \pm 0.60^{* *+\dagger}$ \\
\hline Saline & & $8.43 \pm 1.21^{* *+\dagger}$ & $9.08 \pm 1.28^{* *+\dagger} \quad 9.76 \pm 0.99^{* *+\dagger}$ & $12.1 \pm 1.30^{* *+\dagger}$ & $10.9 \pm 0.84^{* *+\dagger}$ \\
\hline SOD & & $4.73 \pm 0.67^{* * \text { * }}$ & $6.17 \pm 0.57^{* *}$ 枺 $6.36 \pm 0.72^{* * * \text { 杉 }}$ & $10.3 \pm 1.05^{* *+t \neq}$ & $10.0 \pm 1.00^{* *+\dagger \neq}$ \\
\hline MSODa & & $5.73 \pm 0.51^{* * * * *}$ & 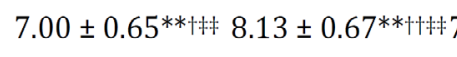 & $\$ 7.36 \pm 0.91^{* *+\dagger+\downarrow \S \S}$ & $\S 7.18 \pm 0.62^{* * \dagger \dagger+\neq} \S \S$ \\
\hline & & & MPO (Units/g) after reperfus & usion & \\
\hline Sham & $0.41 \pm 0.03$ & & & & \\
\hline I & $0.68 \pm 0.05^{*}$ & & & & \\
\hline $\mathrm{I} / \mathrm{R}$ & & $1.05 \pm 0.08^{* *+\dagger}$ & $1.24 \pm 0.08^{* *+\dagger} \quad 1.74 \pm 0.11^{* *+\dagger}$ & $2.41 \pm 0.11^{* *+\dagger}$ & $2.42 \pm 0.11^{* *+\dagger}$ \\
\hline Saline & & $1.05 \pm 0.08^{* *+\dagger}$ & $1.16 \pm 0.09^{* *+\dagger} \quad 1.70 \pm 0.25^{* *+\dagger}$ & $2.41 \pm 0.14^{* *+\dagger}$ & $2.33 \pm 0.15^{* *+\dagger}$ \\
\hline SOD & & $0.65 \pm 0.08^{* *+\dagger}$ & $0.68 \pm 0.09^{* *+\dagger} \quad 0.82 \pm 0.11^{* *+\neq}$ & $1.14 \pm 0.07^{* *+十 \text { 柑 }}$ & $1.14 \pm 0.08^{* *+十^{*}}$ \\
\hline MSODa & & $0.69 \pm 0.08^{* *+\dagger+t}$ & $\neq 0.71 \pm 0.11 * *++\neq \neq 0.85 \pm 0.09 * *+\neq \neq$ & $1.05 \pm 0.07 * *+\uparrow * \neq$ & $1.05 \pm 0.07^{* *+\dagger+\neq}$ \\
\hline
\end{tabular}




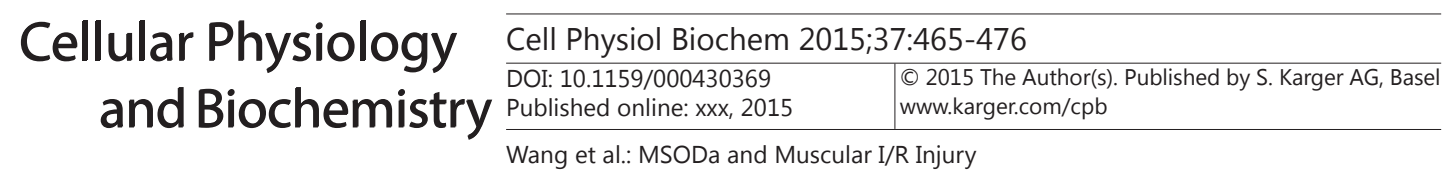

Table 2. Effects of SO) and SOD-modeled coordination compound (MSODa) on increased CD11b/CD18 and intercellular adhesion molecule-1 (ICAM-1) expression in each group before and after ischemia, ischemia/ reperfusion (I/R) injury, . Averaged data were expressed as mean $\pm \mathrm{SD}, n=6$ rats for each group. ${ }^{*} P<0.05$ and ${ }^{* *} P<0.01$ vs sham, ${ }^{\dagger} P<0.05$ and ${ }^{\dagger \dagger} P<0.01$ vs ischemia, ${ }^{\ddagger} P<0.05$ and ${ }^{\ddagger \ddagger} P<0.01$ vs $\mathrm{I} / \mathrm{R},{ }^{\S} P<0.05$ and $\$ \S P<0.01$ vs SOD. Note: Sham: sham operation group; I: ischemia group; I/R: ischemia/reperfusion group; Saline: I/R rats treated with normal saline group; SOD: I/R rats treated with SOD; MSODa: I/R rats treated with MSODa

\begin{tabular}{|c|c|c|c|c|c|c|}
\hline \multicolumn{7}{|c|}{ CD11b/CD18 (\%) after reperfusion } \\
\hline Group & & $1 \mathrm{~h}$ & $2 \mathrm{~h}$ & $4 \mathrm{~h}$ & $8 \mathrm{~h}$ & $12 \mathrm{~h}$ \\
\hline Sham & $22.8 \pm 4.94$ & & & & & \\
\hline I & $24.3 \pm 4.40$ & & & & & \\
\hline $\mathrm{I} / \mathrm{R}$ & & $39.0 \pm 4.82^{* *+\dagger}$ & $46.7 \pm 5.42^{* *+\dagger}$ & $56.6 \pm 10.7^{* *+\dagger}$ & $69.1 \pm 11.8^{* *+\dagger}$ & $48.8 \pm 8.49^{* *++}$ \\
\hline Saline & & $39.2 \pm 3.69^{* *+\dagger}$ & $46.2 \pm 5.47^{* *++}$ & $55.6 \pm 10.2^{* *+\dagger}$ & $68.1 \pm 12.8^{* *+\dagger}$ & $48.6 \pm 12.4^{* *+\dagger}$ \\
\hline SOD & & $26.4 \pm 5.54$ 抹 & $38.3 \pm 3.91^{* *+\text { 十抹 }}$ & $51.9 \pm 6.34^{* *+\dagger \neq}$ & $60.0 \pm 11.2^{* *+1 \neq}$ & $43.9 \pm 12.5^{* *++t}$ \\
\hline MSODa & & $26.5 \pm 5.85$ 抹 & $34.2 \pm 7.22^{\text {* 俦 }}$ & $39.1 \pm 6.15^{* * \dagger \dagger \neq \neq \S ~}$ & $54.3 \pm 4.84^{* *+\dagger \neq \neq £ \S ~}$ & $25.9 \pm 4.42 \neq \neq \S \S$ \\
\hline
\end{tabular}

Fig. 1. Cytometry evaluation of the positive rate of $\mathrm{CD} 11 \mathrm{~b} / \mathrm{CD} 18$ after ischemia (A), at $12 \mathrm{~h}$ after I/R injury (B), I/R model rats treated with SOD (C) or MSODa (D).

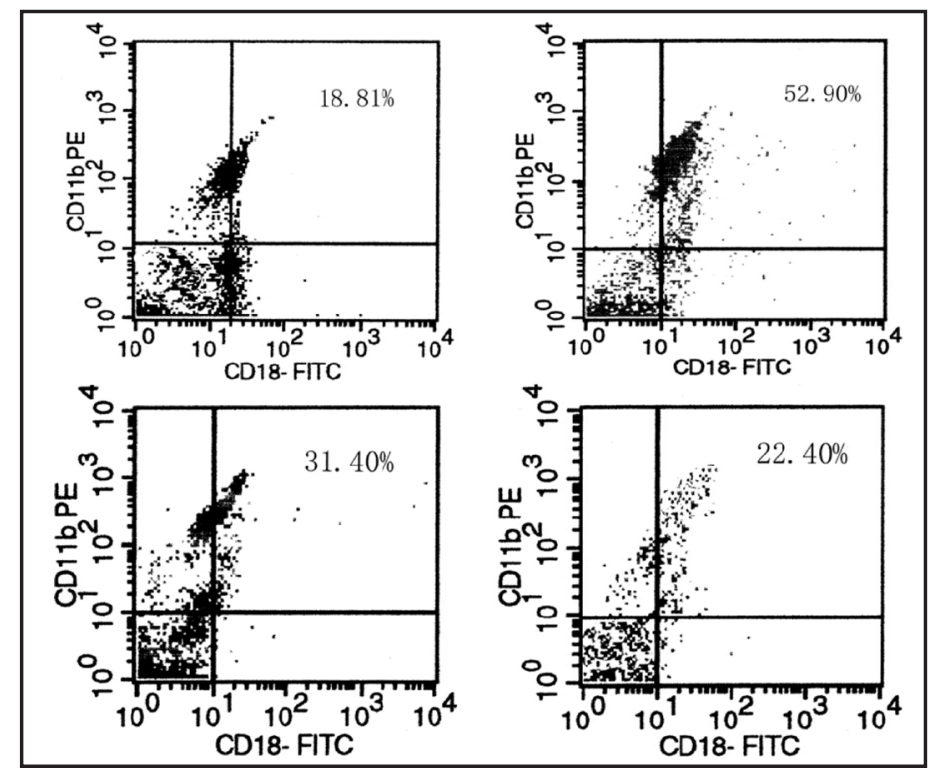

and saline-treated model rats. Intriguingly, the MSODa-treated rats displayed even better plasma measurement of MDA $(P<0.01$ vs SOD) at $8-12 \mathrm{~h}$ after I/R.

Effects of MSODa tissue MPO before and after ischemia/reperfusion injury of skeletal muscle

The MPO is a peroxidase enzyme and most abundantly expressed in neutrophil granulocytes. Since 2003, the MPO has long been served as a sensitive predictor for I/R injury of both cardiac and skeletal muscles $[21,22]$. To evaluate the injured level of skeletal muscle after I/R, the MPO was measured and the averaged data showed that increased MPO was observed in ischemic tissue $(0.68 \pm 0.05, P<0.05$ vs sham) and greatly increased from $150 \%$ up to $350 \%$ at $2 \mathrm{~h}$ and $8 \mathrm{~h}$ followed by the reperfusion with a similar trends during entire reperfusion compared with the alternation of MDA in the same preparation (Table 1). In SOD- and MSODa-treated rats, the tissue levels of MPO were reduced markedly and identically $(P<0.01$ vs I/R or saline).

Effects of MSODa on CD11b/CD18 expression on neutrophils before and after ischemia/ reperfusion injury of skeletal muscle

The CD11b/CD11 belongs to the integrin superfamily and plays a key role in mediating neutrophil-endothelia interaction through ICAM-1 $[23,24]$ during I/R injury in skeletal 


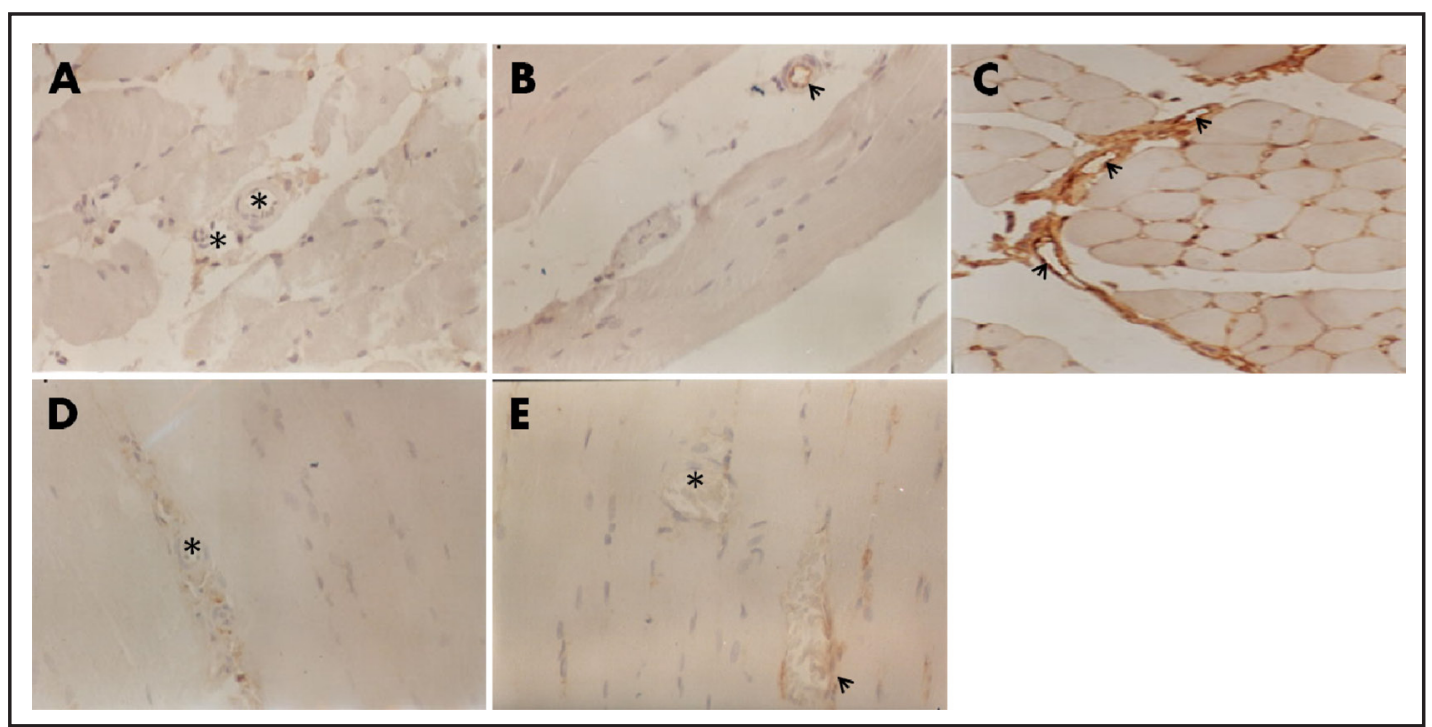

Fig. 2. Immunohistochemical analysis of an angiogenesis in skeletal muscle after I/R injury in rats using SRBC method. (A) control (sham) rats without ICAM-1-positive angiogenesis; (B) ischemic rats with a few ICAM-1-positive angiogenesis (indicated by arrow head); (C) $12 \mathrm{~h} \mathrm{I/R} \mathrm{injury} \mathrm{inducing} \mathrm{a} \mathrm{significant} \mathrm{increase}$ in ICAM-1-positve vasculatures (indicated by arrow head); (D - E) protective effect of MSODa on I/R injury showing weak (indicated by asterisk) or negative ICAM-1 immunoactivity. All images are presented at 400×.

muscle. Therefore, monitoring the dynamic changes of CD11b/CD18 during I/R would provide directly evidence to evaluate the severity of I/R injury by using cytometry. Our data showed that the CD11b/CD18 was significantly upregulated during ischemia $(P>0.01 \mathrm{vs}$ sham, Table 2), but the reperfusion significantly increased the positive rate of CD11b/CD18 $(\sim 160$ up to $200 \%)$ in a time-dependent fashion. Surprisingly, the pretreatment of I/R rats with SOD or MSODa, especially with the later, dramatically reduced increased CD11b/CD18, even back to the normal level in MSODa-treated group at the end of reperfusion process (Table 1 and Fig. 1).

Effects of MSODa on vasculature ICAM-1 expression before and after ischemia/reperfusion injury of skeletal muscle

The ICAM-1 is an adhesion molecule located on the surface of endothelial cell to mediate the adhesion process with CD11b/CD18 (integrin- $\beta 2$ ) on the neutrophil, and sequent cell migration and infiltration [25]. Recent observation has shown that Inhibition of ICAM-1-dependent binding using monoclonal antibodies has been shown to be efficacious in ameliorating I/R injury by preventing the influx of neutrophils into the ischemic tissue [26]. To test if SOD and MSODa reduce ICAM-1 expression, the immunofluorescent staining was performed (Fig. 2) and the results showed that positive immuostaining vasculature was observed in sham-control rats (Fig. 2A, as indicated by *), while, weak and heavy staining of positive immuostaining vasculatures were confirmed in ischemia and I/R model rats (Fig. 2B and $\mathrm{C}$, as indicated by arrow heads), and interestingly, ICAM-1 positive vasculature was almost disappeared when pretreatment with SOD and MSODa (Fig. 2D and E, as indicated by * or arrow head). Averaged data showed that tissue ICAM-1 expression was increased to $23.1 \pm 2.38$ after ischemia as compared with sham, and this data were then further and timedependent increased by $\sim 270 \%$ at $12 \mathrm{~h}$ after the reperfusion followed by ischemia (Table 2).

Morphological changes in skeletal muscle induced by ischemia/reperfusion injury before and after MSODa treatment

As compared with the sham control rats, the skeletal muscle underwent a significant morphological alternation during I/R. At $2 \mathrm{~h}$ after I/R (Fig. 3B and E), the space between 


\section{Cellular Physiology Cell Physiol Biochem 2015;37:465-476 \begin{tabular}{ll|l} 
DOI: 10.1159/000430369 & $\begin{array}{l}\text { O 2015 The Author(s). Published by S. Karger AG, Basel } \\
\text { www.karger.com/cpb }\end{array}$ \\
\cline { 2 - 2 }
\end{tabular}
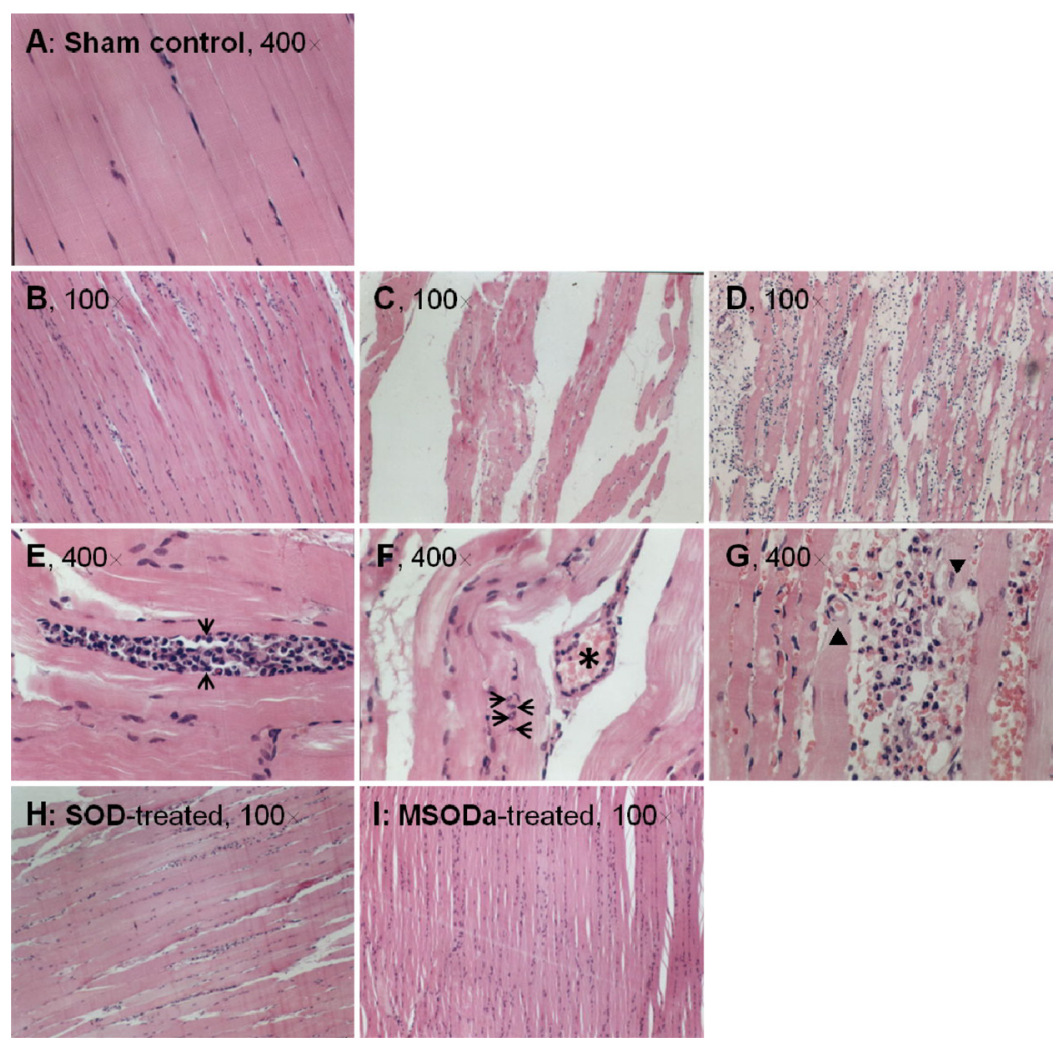

Fig. 3. Morphological changes of skeletal muscle after I/R injury under the light microscope. (A) sham control rats showing normal arrangement of skeletal muscles with clear bands and no white blood cell infiltration; (B and E) morphological changes at $2 \mathrm{~h}$ after muscular I/R injury under low (100×) and high magnification $(400 \times)$; neutrophil accumulation can be observed in the vasculature under high power (between the arrow heads); ( $\mathrm{C}$ and F) morphological changes at $4 \mathrm{~h}$ after muscular I/R injury showing abnormal arrangement of muscular fibers with enlarged intracellular space and significant interstitial edema under both amplifications, significant adhesion of neutrophils on the surface of endothelium (indicated by the asterisk) and tissue infiltration (indicated by arrow heads) identified under high power; (D and G) morphological alternations at $8 \mathrm{~h}$ after muscular I/R injury showing significant migration of white blood cells into interstitial space and tissue infiltration under both amplifications; irregular shape and enlargement of skeletal muscle with unclear bands and broken ends (indicated by $\boldsymbol{\nabla}$ or $\boldsymbol{\Delta}$ ), marked focal myolysis with large amount of neutrophil accumulation; (H) protective effect of SOD on I/R-induced morphological injury observed in skeletal muscles of rats showing near normal arrangement of skeletal muscles with slight enlarged intramuscular space and interstitial edema and not significant white blood cell accumulation within vasculature and tissue infiltration; (I) protective effect of MSODa on I/R-induced morphological injury observed in skeletal muscles of rats showing near normal arrangement of skeletal muscle with clear bands, slight interstitial edema without cell infiltration.

muscular fibers were enlarged, obvious interstitial edema could be observed, and large amount of white blood cells were accumulated in venules with no reflow. Upon $4 \mathrm{~h}$ after I/R (Fig. 3C and F), based on the morphological changes occurred at $2 \mathrm{~h}$ after I/R, the muscular fiber gap was further aggravated, venules was dilated with significant white blood cells adhesion on the entire surface of the endothelium with clear tissue migration of neutrophil. Along with the reperfusion up to $8 \mathrm{~h}$ (Fig. 3D and G), the myolysis and broken muscular fibers (as indicated by $\boldsymbol{\Delta}$ or $\boldsymbol{\nabla}$ ) were observed with blur bands and more severe muscular edema. Intriguingly, all morphological changes induced by I/R mentioned above were dramatically improved in SOD-treated or MSODa-treated rats (Fig. 3H or 3I).

\section{KARGER}




\section{Cellular Physiology}

and Biochemistry Published online: $x x \times 1,2015$

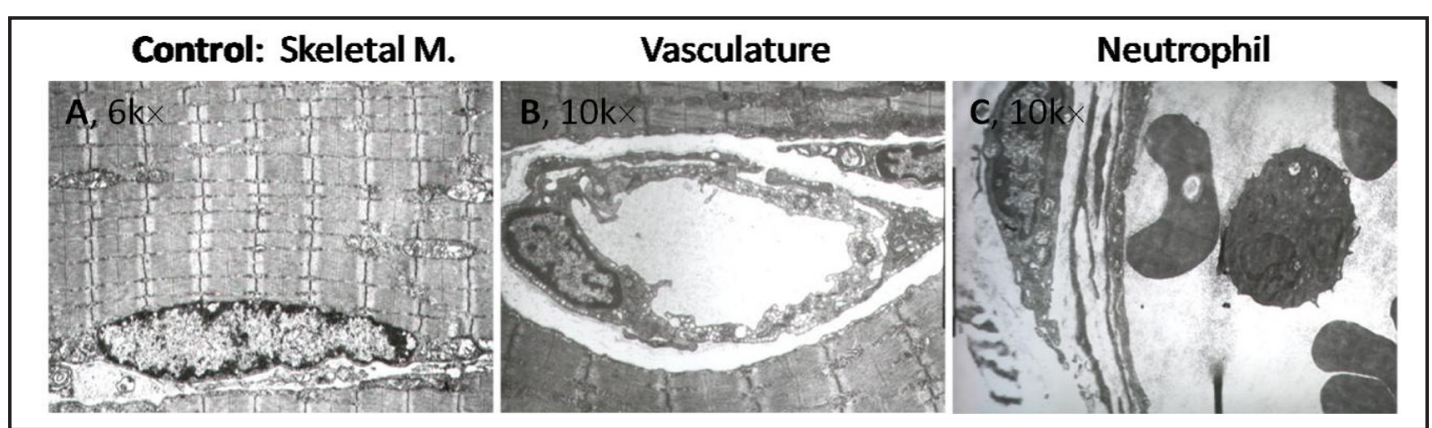

Fig. 4. Normal ultrastructure of skeletal muscles, vasculature, and white blood cells in control rats. (A) the skeletal muscles show normal arrangement with clear bands with a spindle shape of nucleus and large amount of mitochondria around nucleus and glycogens between intermuscular muscle fibers. (B) The endothelial integrity and the diameter of vessel are in good shape. (C) Neutrophils show near round shape with slight wrinkles on the surface.

Fig. 5. Changes in ultrastructure in of skeletal muscles after ischemia/ reperfusion injury, and protective effects of SOD and MSODa in rats. (A and B) typical changes after ischemia; (C - E) typical changes at $4 \mathrm{~h}$ after I/R injury; (F - H) typical changes at $8 \mathrm{~h}$ after I/R injury; (I - J) Protective effects of SOD on I/R injury; (K - M) Protective effects of MSODa on I/R injury.

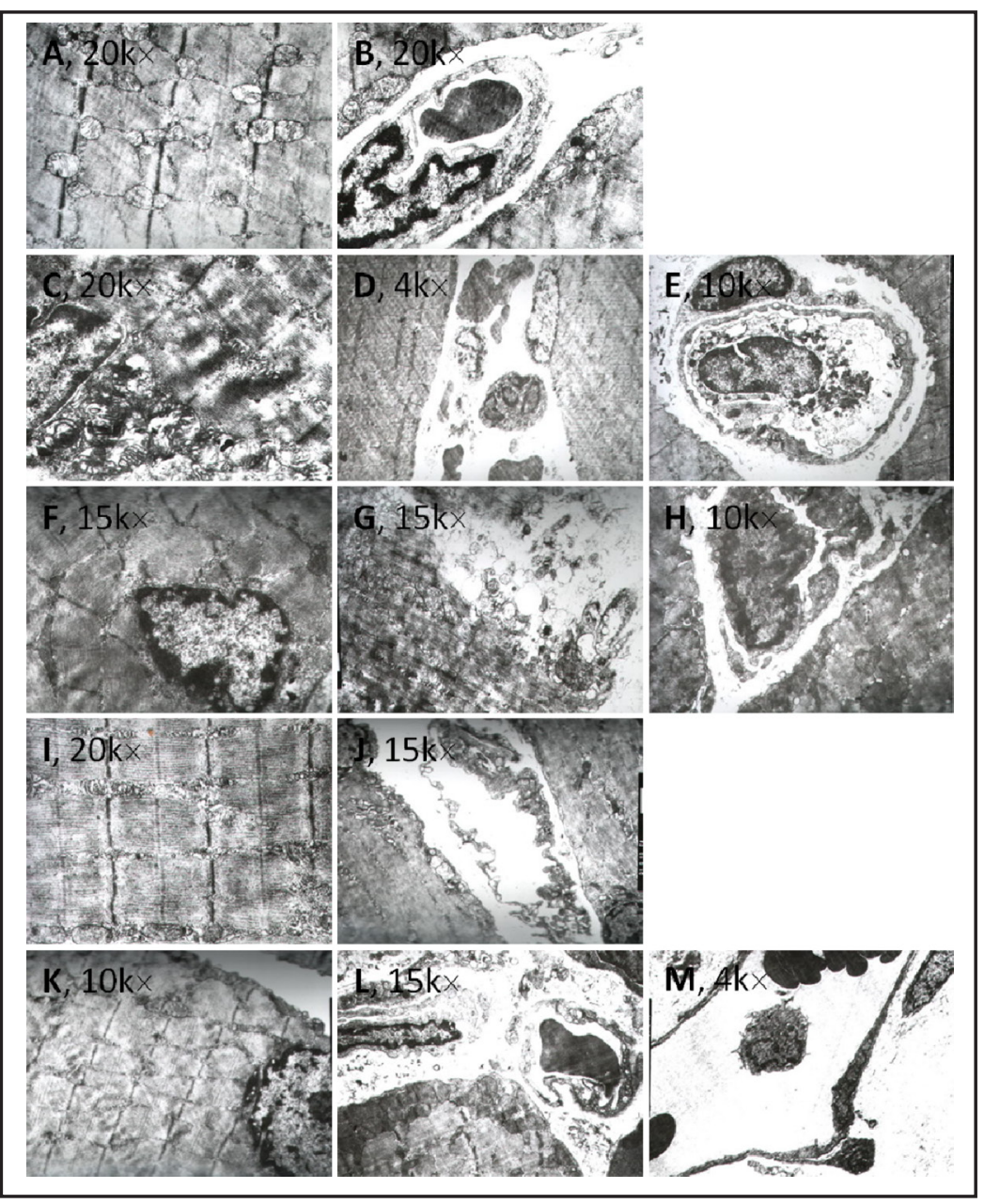

Effects of MSODa on ultrastructure changes in skeletal muscle before and after ischemia/ reperfusion injury

In order to verify the morphological changes induced by I/R and protective effects of SOD or MSODa, the ultrastructural examination was also conducted using emission electromicroscope (EM) and the results indicated that, in sham control rats, the sarcomere arrangement was in alignment with clear bands, the spindle shape nucleus surrounded with mitochondria, and abundant glycogens between muscular fibers (Fig. 4A); The endothelial 
integrity of vasculature was observed with proper diameter (Fig. 4B); the ball-shaped neutrophil could also be seen in the center of the lumen with slight wrinkles on the surface (Fig. 4C).

Undergoing the ischemia (Fig. 5A and B), the arrangement of muscular fibers were remain in order with slight fuzzy bands, weak mitochondrial swelling, and reduced glycogens, as well as the vessel wall thickening with contracted status and the heterochromatin marginalization and less pinocytosis vesicles. As expected, all morphological alternations mentioned above were aggravated progressively along with the reperfusion, manifested as increased gap of muscular fibers with significant fuzzy bands, focal muscular dissolution, vacuolar mitochondria, few glycogens surroundings, neutrophil tissue infiltration, and no reflow phenomenon with a likelihood irregular and stiffness of neutrophil membrane, and intermittent endothelium (Fig. 5C-E) at $4 \mathrm{~h}$ after I/R; Furthermore, by increasing the reperfusion time up to $12 \mathrm{~h}$ after ischemia (Fig. 5F-H), the more severer morphological changes were occurred, showing that the shape of the nucleus for skeletal muscle was changed with obvious migration into muscular tissue, the structure of sarcomere became dimness, and the muscular fibers were not in alignment with dramatic fuzzy bands, large scale of dissolution, and mitochondria vacuolar degeneration; additionally, the nucleus of endothelia projected into the lumen, the vascular integrity was further and significantly damaged.

Surprisingly, the mentioned morphological changes were significantly improved by pretreatment of I/R rats with either SOD (Fig. 5 I and J) or MSODa (Fig. 5K-M).

\section{Discussion}

Major findings and potential clinical impacts

Using an established rat model of experimentally induced I/R injury of skeletal muscle in the left hind leg, we have shown that the SOD and MSODa, an artificially synthesed compound $\mathrm{Cu}_{2}\left(\mathrm{C}_{3} \mathrm{~N}_{2} \mathrm{H}_{4}\right)_{6}\left(\mathrm{C}_{3} \mathrm{H}_{2} \mathrm{H}_{2}\right) \mathrm{Cl}_{3}$ based upon the natural $\mathrm{Cu}-\mathrm{Zn}(\mathrm{Cu}-\mathrm{ZnSOD}$ ), exhibit a significant protective effects against I/R-induced oxidative stress through the reduction in expression of integrin (CD11b/CD18) and adhesion molecule (ICAM-1) on neutrophil and endothelium leading to less adhesion, migration, and tissue infiltration, and resulting in an attenuation of neutrophil-mediated no reflow and tissue dissolution. Importantly, the dynamic changes in pathophysiological expression of both integrin and adhesion molecule are well paralleled with the time course of MDA and MPO changing, and morphological alternations as well during I/R injury. The MDA and MPO are the metabolic products of lipid peroxidation, and the correlation analysis for MDA vs CD11b/CD18 and ICAM-1 demonstrated that the regression coefficients $\left(r^{2}\right)$ are 0.34 and 0.24 , respectively, for SOD, and 0.48 and 0.39 , respectively, in the case of MSODa. These observations strongly suggest that SOD and MSODa play a critical role in protective against I/R injury in rat skeletal muscle preparation and interestingly, the advantage and prospective of MSODa may become the first priority in clinical application due mainly to its SOD-like activity, no cost-quality tradeoff profile, and physicochemical characteristics, such as molecular size, easiness crossing the membrane, and lesser immunogenicity as compared with native SOD [27].

\section{$I / R$ mediated oxidative stress in skeletal muscle}

The oxidative stress and free radicals are key players in I/R-mediated microvasculature [28] and muscular cell injuries [29, 30]. Whereas, the neutrophils contribute significantly to I/R-mediated tissue and cellular damage [31,32] via toxic free radicals release during adhesion, migration and tissue infiltration. During this pathophysiological processes of I/R, the adhesion molecules including CD11b/CD18 on neutrophil [33, 34] and ICAM-1 [34, 35] on endothelium are the most important mediators. Our current study showed that both plasma CD11b/CD18 and tissue ICAM-1 increased significantly and progressively during $\mathrm{I} / \mathrm{R}$, consistent and paralleled well with the time course of MDA and MPO measurements, 


\section{Cellular Physiology Cell Physiol Biochem 2015;37:465-476 \begin{tabular}{l|l} 
DOI: 10.1159/000430369 & $\begin{array}{l}\text { O 2015 The Author(s). Published by S. Karger AG, Basel } \\
\text { www.karger.com/cpb }\end{array}$ \\
and Biochemistry Published online: xxx, 2015 & Pang
\end{tabular} \\ Wang et al.: MSODa and Muscular I/R Injury}

and morphological observations as well regarding the alternations in skeletal muscle, vasculature, and neutrophil, suggesting the great contribution of neutrophil-orientated free radicals to I/R injury and the close involvement of both CD11b/CD18 and ICAM-1 in this pathophysiological process.

\section{Advantage and prospective of MSODa}

The SOD are the native enzymes that alternately catalyze the dismutation (or partitioning) of the superoxide $\left(\mathrm{O}_{2}^{-}\right)$radical into either ordinary molecular oxygen $\left(\mathrm{O}_{2}\right)$ or hydrogen peroxide $\left(\mathrm{H}_{2} \mathrm{O}_{2}\right)$. Superoxide is produced as a by-product of oxygen metabolism and, if not regulated, causes many types of cell damage. Mice lacking SOD develop a wide range of pathology, including cancer, an acceleration of age-related muscle mass loss, and earlier incidence of cataracts and reduced lifespan, even die several days after birth [3639]. Thus, the SOD is an integral part of antioxidant defense in nearly all living cells exposed to oxygen. In our observation, the SOD significantly reduces the plasma MDA and tissue MPO, at the meantime, attenuates the expression of adhesion molecules, including CD11b/ CD18 on neutrophils and ICAM-1 on endothelium, and importantly, reverses in parallel the morphological alternations. Surprisingly, the MSODa, a synthesized modeled coordination compound upon the active center of $\mathrm{Cu}-\mathrm{ZnSOD}$ displays even better protective effects in all aspects against I/R injury in skeletal muscle preparation. Moreover, other property of MSODa, such as dramatically smaller size of the molecule (M.W.: 708.5) compared with SOD (32000 40000), which makes MSODa easily being transported through the membrane. Additionally, the immunogenicity is an other key issue to limit native SOD to be widely used in clinically because it is commonly obtained from bovine liver, however, the immunogenicity for MSODa would be significant lesser than that of native SOD, which would greatly benefit to all patients with indications. Finally, the cost for utilizing the MSODa is tremendously reduced compared with getting the native SOD.

\section{Acknowledgements}

This study was supported by the National Natural Science Foundation of China (grant Nos. 81371977, 81272014). The authors would like to thank the technical help from the Key Laboratory of Myocardial Ischemia of Harbin Medical University, Ministry of Education, and Heilongjiang Province, China.

\section{Disclosure Statement}

No conflict of interests.

\section{References}

1 Sacks JM, Kuo YR, Horibe EK, Hautz T, Mohan K, Valerio IL, Lee WP: An optimized dual-surgeon simultaneous orthotopic hind-limb allotransplantation model in rats. J Reconstr Microsurg 2012;28:69-75.

2 Lowrie AG, Berry MG, Kirkpatrick JJ, Lees VC, McGrouther DA: Arterial injuries at the elbow carry a high risk of muscle necrosis and warrant urgent revascularisation. Ann R Coll Surg Engl 2012;94:124-128.

3 Codding JL, Vosbikian MM, Ilyas AM: Acute Compartment Syndrome of the Hand. J Hand Surg Am 2015;40:1213-1216.

4 Barshes NR, Pisimisis G, Kougias P: Compartment syndrome of the foot associated with a delayed presentation of acute limb ischemia. J Vasc Surg DOI: 10.1016/j.jvs.2015.01.043.

5 Raza H, Mahapatra A: Acute compartment syndrome in orthopedics: causes, diagnosis, and management. Adv Orthop 2015;2015:543412. 


\section{Cellular Physiology Cell Physiol Biochem 2015;37:465-476 \begin{tabular}{l|l} 
DOI: 10.1159/000430369 & $\begin{array}{l}\text { O 2015 The Author(s). Published by S. Karger AG, Basel } \\
\text { www.karger.com/cpb }\end{array}$ \\
and Biochemistry Published online: xxx, 2015 & Pang
\end{tabular} \\ Wang et al.: MSODa and Muscular I/R Injury}

6 Schmidt Y, Bannasch H, Eisenhardt SU: Ischemia-reperfusion injury leads to significant tissue damage in free flap surgery. Plast Reconstr Surg 2012;129:174e-175e.

7 Burn BR, Varner KJ: Environmentally persistent free radicals compromise left ventricular function during ischemia/reperfusion injury. Am J Physiol Heart Circ Physiol 2015;308:H998-H1006.

8 Gute DC, Ishida T, Yarimizu K, Korthuis RJ: Inflammatory responses to ischemia and reperfusion in skeletal muscle. Mol Cell Biochem 1998;179:169-187.

9 Anderson BO, Brown JM, Harken AH: Mechanisms of neutrophil-mediated tissue injury. J Surg Res 1991;51:170-179.

10 Ni NC, Ballantyne LL, Mewburn JD, Funk CD: Multiple-site activation of the cysteinyl leukotriene receptor 2 is required for exacerbation of ischemia/reperfusion injury. Arterioscler Thromb Vasc Biol 2014;34:321330.

11 Hiroi T, Wajima T, Negoro T, Ishii M, Nakano Y, Kiuchi Y, Mori Y, Shimizu S: Neutrophil TRPM2 channels are implicated in the exacerbation of myocardial ischaemia/reperfusion injury. Cardiovasc Res 2013;97:271281.

12 Concannon MJ, Dooley TW, Puckett CL: Improved survival in a replantation model containing ischemic muscle. Microsurgery 1991;12:18-22.

13 Korthuis RJ, Gute DC: Postischemic leukocyte/endothelial cell interactions and microvascular barrier dysfunction in skeletal muscle: cellular mechanisms and effect of Daflon 500 mg. Int J Microcirc Clin Exp 1997;17:11-17.

14 Jerome SN, Kong L, Korthuis RJ: Microvascular dysfunction in postischemic skeletal muscle. J Invest Surg 1994;7:3-16.

15 Zengin E, Sinning C, Zeller T, Rupprecht HJ, Schnabel RB, Lackner KJ, Blankenberg S, Westermann D, Bickel C: Activity of superoxide dismutase copper/zinc type and prognosis in a cohort of patients with coronary artery disease. Biomark Med 2015;9:597-604.

16 Yeh DY, Tung SP, Fu YH, Yang YC, Wang JJ: Intravenous superoxide dismutase administration reduces contralateral lung injury induced by unilateral lung ischemia and reperfusion in rats through suppression of activity and protein expression of matrix metalloproteases. Transplant Proc 2015;47:1083-1086.

17 Zhao R, Yue JJ, Liu XH, Yin YX, Liu XL, Miao FM: Studies on the synthesis and activities of Cu,Zn superoxides dismutase mimic complexes. J Tianjin Normal Univ 2001;21:1-5.

18 Moore K, Roberts LJ, 2nd: Measurement of lipid peroxidation. Free Radic Res 1998;28:659-671.

19 Del Rio D, Stewart AJ, Pellegrini N: Pellegrini, A review of recent studies on malondialdehyde as toxic molecule and biological marker of oxidative stress. Nutr Metab Cardiovasc Dis 2005;15:316-328.

20 Senturk T, Cavun S, Avcı B, Yermezler A, Serdar Z, Savcı V: Effective inhibition of cardiomyocyte apoptosis through the combination of trimetazidine and $\mathrm{N}$-acetylcysteine in a rat model of myocardial ischemia and reperfusion injury. Atherosclerosis 2014;237:760-766.

21 Huang T, Wang W, Tu C, Yang Z, Bramwell D, Sun X: Hydrogen-rich saline attenuates ischemia-reperfusion injury in skeletal muscle. J Surg Res 2015;194:471-480.

22 Brennan ML, Penn MS, Van Lente F, Nambi V, Shishehbor MH, Aviles RJ, Goormastic M, Pepoy ML, McErlean ES, Topol EJ, Nissen SE, Hazen SL: Prognostic value of myeloperoxidase in patients with chest pain. N Engl J Med 2003;349:1595-1604.

23 Seekamp A, Mulligan MS, Till GO, Smith CW, Miyasaka M, Tamatani T, Todd RF 3rd, Ward PA: Role of beta 2 integrins and ICAM-1 in lung injury following ischemia-reperfusion of rat hind limbs. Am J Pathol 1993;143:464-472.

24 Pahl MV, Vaziri ND, Connall T, Morrison D, Kim C, Kaupke CJ, Wilson SE: Systemic upregulation of leukocyte integrins in response to lower body ischemia-reperfusion during abdominal aortic aneurysm repair. J Natl Med Assoc 2005;97:172-179.

25 Sans M, Panés J, Ardite E, Elizalde JI, Arce Y, Elena M, Palacín A, Fernández-Checa JC, Anderson DC, Lobb R, Piqué JM: VCAM-1 and ICAM-1 mediate leukocyte-endothelial cell adhesion in rat experimental colitis. Gastroenterology 1999;116:874-883.

26 Merchant SH, Gurule DM, Larson RS: Amelioration of ischemia-reperfusion injury with cyclic peptide blockade of ICAM-1. Am J Physiol Heart Circ Physiol 2003;284:H1260-H1268.

27 Noda J, Otagiri M, Akaike T, Maeda H: Pharmacological advantages of conjugation of Cu, Zn-superoxide dismutase with succinylated keratin fragment: improvement of biological properties and resistance to oxidative damage. J Pharmacol Exp Ther 1996;279:162-171. 


\section{Cellular Physiology Cell Physiol Biochem 2015;37:465-476

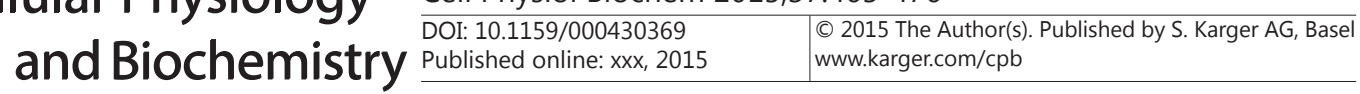 \\ Wang et al.: MSODa and Muscular I/R Injury}

28 Brault S, Martinez-Bermudez AK, Marrache AM, Gobeil F Jr, Hou X, Beauchamp M, Quiniou C, Almazan G, Lachance C, Roberts J 2nd, Varma DR,Chemtob S: Selective neuromicrovascular endothelial cell death by 8-Iso-prostaglandin F2alpha: possible role in ischemic brain injury. Stroke 2003;34:776-782.

29 Atahan E, Ergun Y, Belge Kurutas E, Cetinus E, Guney Ergun U: Ischemia-reperfusion injury in rat skeletal muscle is attenuated by zinc aspartate. J Surg Res 2007;137:109-116.

30 Wang R, Liu YY, Liu XY, Jia SW, Zhao J, Cui D, Wang L: Resveratrol protects neurons and the myocardium by reducing oxidative stress and ameliorating mitochondria damage in a cerebral ischemia rat model. Cell Physiol Biochem 2014;34:854-864.

31 Du J, Shen X, Zhao Y, Hu X, Sun B, Guan W, Li S, Zhao Y: Wip1-deficient neutrophils significantly promote intestinal ischemia/reperfusion injury in mice. Curr Mol Med 2015;15:100-108.

32 Li X, Huo X, Zhang C, Ma X, Han F, Wang G: Role of continuous high thoracic epidural anesthesia in hippocampal apoptosis after global cerebral ischemia in rats. Cell Physiol Biochem 2014;34:1227-1240.

33 Granger DN, Benoit JN, Suzuki M, Grisham MB: Leukocyte adherence to venular endothelium during ischemia-reperfusion. Am J Physiol 1989;257:G683-G688.

34 Nolte D, Hecht R, Schmid P, Botzlar A, Menger MD, Neumueller C, Sinowatz F, Vestweber D, Messmer K: Role of Mac-1 and ICAM-1 in ischemia-reperfusion injury in a microcirculation model of BALB/C mice. Am J Physiol 1994;267:H1320-H1328.

35 Diamond MS, Staunton DE, Marlin SD, Springer TA: Binding of the integrin Mac-1 (CD11b/CD18) to the third immunoglobulin-like domain of ICAM-1 (CD54) and its regulation by glycosylation. Cell 1991;65:961971.

36 Li Y, Huang TT, Carlson EJ, Melov S, Ursell PC, Olson JL, Noble LJ, Yoshimura MP, Berger C, Chan PH, Wallace DC, Epstein CJ: Dilated cardiomyopathy and neonatal lethality in mutant mice lacking manganese superoxide dismutase. Nat Genet 1995;11:376-381.

37 Elchuri S, Oberley TD, Qi W, Eisenstein RS, Jackson Roberts L, Van Remmen H, Epstein CJ, Huang TT: CuZnSOD deficiency leads to persistent and widespread oxidative damage and hepatocarcinogenesis later in life. Oncogene 2005;24:367-380.

38 Muller FL, Song W, Liu Y, Chaudhuri A, Pieke-Dahl S, Strong R, Huang TT, Epstein CJ, Roberts LJ 2nd, Csete M, Faulkner JA, Van Remmen H: Absence of CuZn superoxide dismutase leads to elevated oxidative stress and acceleration of age-dependent skeletal muscle atrophy. Free Radic Biol Med 2006;40:1993-2004.

39 Sentman ML, Granström M, Jakobson H, Reaume A, Basu S, Marklund SL: Phenotypes of mice lacking extracellular superoxide dismutase and copper- and zinc-containing superoxide dismutase. J Biol Chem 2006;281:6904-6909. 